\title{
Thermal Hydrocracking of Indan. Effects of the Hydrogen Pressure on the Kinetics and Arrhenius Parameters
}

\author{
M. VAN BOVEN, G. J. ROSKAM, and J. M. L. PENNINGER* \\ Department of Chemical Engineering, Twente University of Technology, Enschede, The Netherlands
}

\begin{abstract}
The kinetics of the thermal hydrocracking of indan were investigated in a high-pressure flow reactor at temperatures from 470 to $530^{\circ} \mathrm{C}$, total pressures of up to $300 \mathrm{~atm}$, and molar ratios from 3 to 40 . The effect of the hydrogen pressure was reflected especially in a change of the experimental rate equations for the formation of toluene from $r_{\mathrm{T}}=k$ [indan] 0.5 [hydrogen] to $r_{\mathrm{T}}=k^{\prime}$ [indan] ${ }^{0.75}$ [hydrogen] ${ }^{0.75}$ with hydrogen partial pressure increasing from 73 to $230 \mathrm{~atm}$. The rate equation of $n$-propylbenzene remained constant at $r_{\mathrm{Pr}}=k^{\prime \prime}$ [indan] [hydrogen] 1.5. Simultaneously the Arrhenius parameters of toluene changed significantly, while those of $n$-propylbenzene remained unchanged.

The observed effect of the hydrogen pressure is explained as a change in the rates of the intermediate reactions; it provides an excellent agreement between the theoretical and experimental data. It was found that the steady-state concentration of the hydrogen atoms, which act as chain carriers in the thermal hydrocracking, was much smaller than the thermodynamic equilibrium concentrations
\end{abstract}

\section{Introduction}

Indan has been reported previously [1] as an attractive model substance for the study of details of the reactions involved in the hydrocracking of polyaromatic compounds [2-4]. The main reaction of indan in thermal hydrocracking, the $\alpha$ ring opening, is a chain reaction and results in the primary cracking products toluene, n-propylbenzene, and ethene/ethane, their reaction rates depending on both the indan and hydrogen partial pressures.

The mechanism postulated previously [1] for the $\alpha$ ring opening (Figure 1) illustrates the particular role of hydrogen. For hydrogen pressures below 100 atm and temperatures ranging from 480 to $540^{\circ} \mathrm{C}$, the equilibrium reactions (2) and (3) are assumed to be fast compared with reactions (4) and (5). Under these conditions good agreement was found between the thereotical rate equations [Table $\mathrm{I}(\mathrm{a})]$ and the experimental equation, namely,

$$
r_{\mathrm{T}}=k_{\mathrm{T}}[\text { indan }]^{0.5}[\text { hydrogen }]
$$

*Present address: AKZ0 Chemie B. V., P. O. Box 247, Amersfoort, The Netherlands.

(C) 1975 by John Wiley \& Sons, Inc. 
and

$$
r_{\mathrm{Pr}}=k_{\mathrm{Pr}}[\text { indan] [hydrogen }]^{1.5}
$$

However, a consequence of the same mechanism is that for hydrogen pressures significantly exceeding $100 \mathrm{~atm}$ reactions (4) and (5) will be faster than the rate of establishment of the equilibria (2) and (3), so that merely a set of irreversible reactions remains. It results in a different kinetic picture, expressing itself not only in the reaction orders, but also in the Arrhenius parameters. For experimental evidence the thermal hydrocracking of indan was studied especially in relation to the temperature and partial pressures of hydrogen and indan in a range of total pressures of up to 300 bar, which is well in excess of reported data [1].

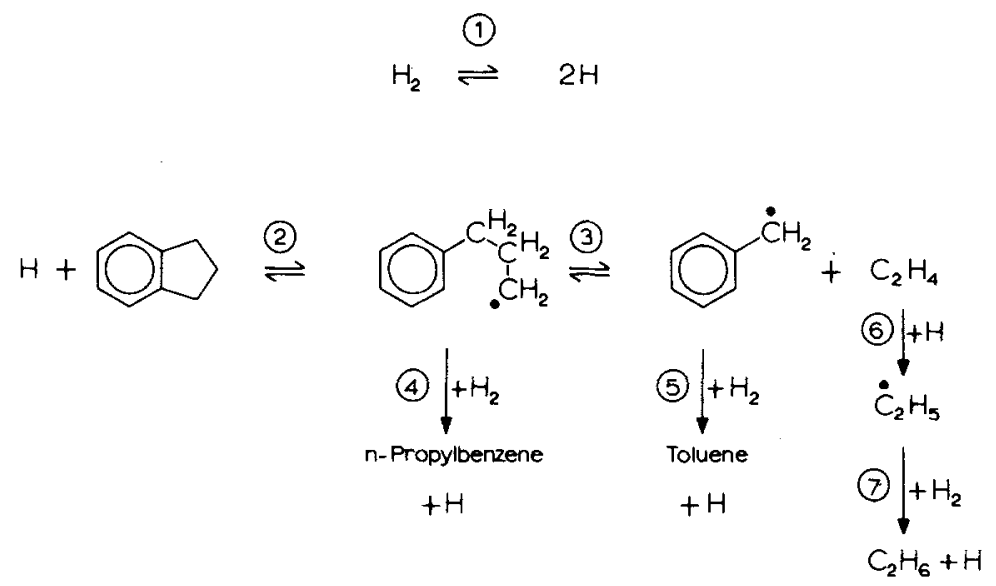

Figure 1. $\alpha$ ring-opening mechanism in thermal hydrocracking of indan.

\section{Experimental}

All experiments were carried out under flow conditions; the typical equipment was described previously [1]. The reactor (inside length $200 \mathrm{~mm}$, inner diameter $8 \mathrm{~mm}$ ) was made from stainless steel containing $0.1 \%$ titanium. Hydrogen and indan were preheated and mixed before entering the reactor. The temperature of the reactor wall and of the reactants in the center of the reactor were measured with calibrated chromel-alumel thermocouples (Thermocoax, outer diameter 1 $\mathrm{mm}$ ) and controlled with $1{ }^{\circ} \mathrm{C}$. The space time (i.e., reaction time) was controlled with an accuracy of approximately $1 \%$.

During a run several samples were taken from the reactor effluent immediately at the outlet of the reactor. This enabled a strict control on the steady-state operation of the reactor. The samples were analyzed by gas-liquid chromatography $\left(10 \%\right.$ polyphenylether on chromosorb $68-80$ mesh, $2 \mathrm{~mm}$ by $\frac{1}{4}$ inch, 
$130^{\circ} \mathrm{C}$, hot wire detector) with mesitylene as an internal standard added to the samples. Indan was made by hydrogenation of indene (Fluka, purum) over $5 \%$ $\mathrm{Pd} / \mathrm{C}$ and $200 \mathrm{~atm}$ hydrogen at $20^{\circ} \mathrm{C}$. It had a gas-liquid chromatography purity of $99.5 \%$ and was dried over activated mole sieves. Hydrogen (Hoek N. V., Rotterdam) had impurities (such as $\mathrm{N}_{2} 100 \mathrm{ppm}, \mathrm{O}_{2} 5 \mathrm{ppm}$, hydrocarbons $5 \mathrm{ppm}$, CO $5 \mathrm{ppm}$, and $\mathrm{CO}_{2} 5 \mathrm{ppm}$, (according to manufacturer's specifications) and was used without further pretreatment. The experiments were done in the following range of reaction conditions: temperature $470-530^{\circ} \mathrm{C}$, total pressure 34-300 atm (the limit being set by the high-pressure facilities), molar ratio hydrogen-indan 3.5-40, and reaction times 50 seconds. All relevant kinetic data were obtained under closely controlled steady-state aging conditions of the reactor wall. The conversion of indan did not exceed $5 \%$ and was regarded as differential.

\section{Results}

The initial formation rates of toluene and $n$-propylbenzene were measured at $500^{\circ} \mathrm{C}$ dependent on the total pressure, which increases from 54 to $300 \mathrm{~atm}$, while the molar ratio hydrogen-indan was held constant at 10 .

The formation rates can be written, at least in a formal way, as ${ }^{1}$

$$
r_{T}=k_{\mathrm{T}}[\text { indan }]^{a}[\text { hydrogen }]^{b}
$$

and

$$
r_{\mathrm{Pr}}=k_{\mathrm{Pr}}[\text { indan }]^{c}[\text { hydrogen }]^{d}
$$

At a constant molar ratio of 10 , [hydrogen] can be substituted by 10 [indan] so that eqs. (III) and (IV) rearrange to

$$
r_{\mathrm{T}}=k_{\mathrm{T}} 10^{b}[\text { indan }]^{a}+b
$$

and

$$
r_{\mathrm{Pr}}=k_{\mathrm{Pr}} 10^{d}[\text { indan }]^{c}+b
$$

A plot of $\ln r$ versus $\ln$ [indan] gives values for the total orders $(a+b)$ and $(c+d)$. As Figure 2 shows, they fit excellently to 1.5 and 2.5, respectively, over the entire pressure range of up to $200 \mathrm{~atm}$, and they are in good agreement with the individual values of $a, b, c$, and $d$, found for hydrogen pressures below $100 \mathrm{~atm}$ [see eqs. (I) and (II)].

For pressures in excess of 100 atm $a, b, c$, and $d$ were found by measuring the formation rates of toluene and $n$-propylbenzene as a function of the indan partial

\footnotetext{
$1 r$ is expressed in mole/1. $\cdot \sec [X]$ concentration of compound $X$ in mole/l.
} 


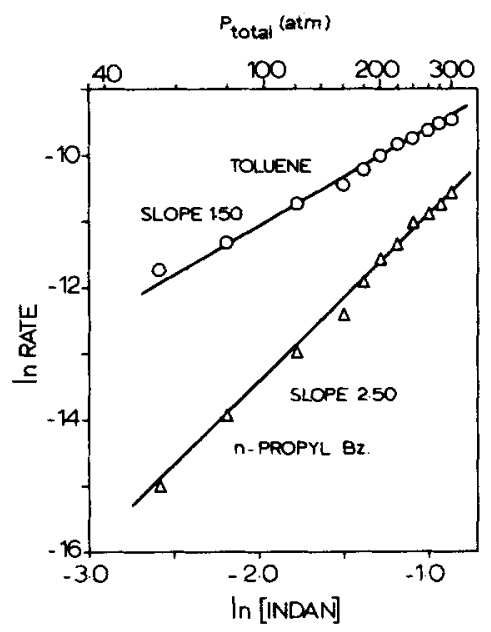

Figure 2. Total order plot for formation rate of toluene and $n$-propylbenzene. Temperature $500^{\circ} \mathrm{C}$, molar ratio hydrogen-indan 10 , indan pressures 4.72 $22.8 \mathrm{~atm}(=0.075-0.422 \mathrm{~mole} / \mathrm{l}$. $)$.

pressure, while the partial pressure of hydrogen was held constant at 209 atm. The data were plotted in Figures 3 and 4 according to the formal rate equations

$$
r_{\mathbf{T}}=k_{\mathbf{T}}{ }^{\prime}[\text { indan }]^{a}, \quad k_{\mathbf{T}}{ }^{\prime}=k_{\mathbf{T}}\left[\mathrm{H}_{\mathbf{2}}\right]^{b}
$$

and

$$
\left.r_{\mathrm{Pr}}=k_{\mathrm{Pr}^{\prime}} \text { [indan }\right]^{c}, \quad k_{\mathbf{P r}^{\prime}}=k_{\mathrm{Pr}}\left[\mathrm{H}_{2}\right]^{d}
$$

The rate data of propylbenzene gave a linear correlation with the indan partial pressure when $c$ had the value of 1 . Consequently the order in hydrogen is 1.5

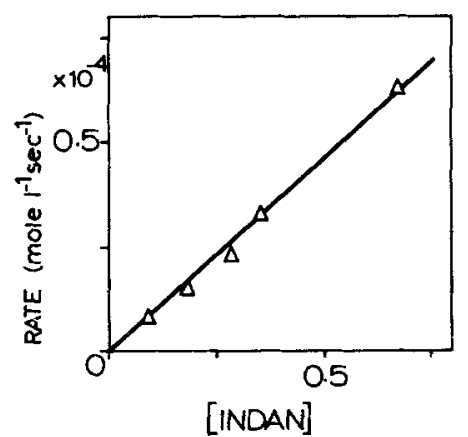

Figure 3. Indan order plot for formation of $n$-propylbenzene. Temperature $500^{\circ} \mathrm{C}$, hydrogen pressure constant at $209 \mathrm{~atm}(=3.19$ mole $/ 1$. $)$, indan pressures $5.9-41.0 \mathrm{~atm}(=0.093-0.91 \mathrm{~mole} / \mathrm{l}$. $)$. 


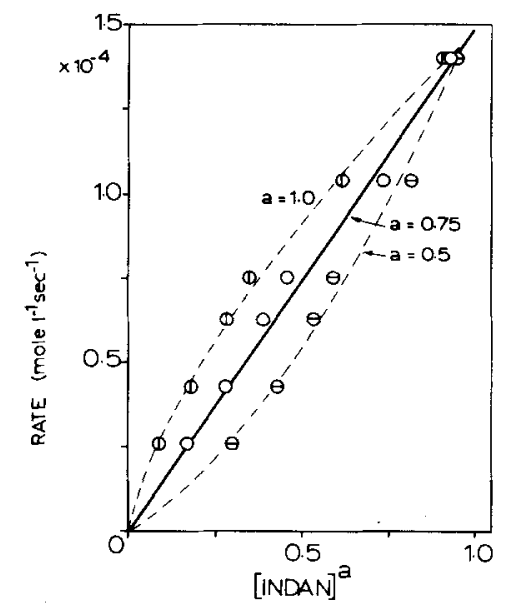

Figure 4. Indan order plot for formation of toluene. Conditions as in Figure 3.

in order to provide a total order of 2.5. Thus the kinetics of $n$-propylbenzene remain the same also for hydrogen partial pressures of up to $210 \mathrm{~atm}$.

This was not found to be the case with toluene. As can be seen from Figure 4 , a linear correlation was not found at an order of 0.5 , the value for hydrogen pressures below $100 \mathrm{~atm}$, but at a slightly higher order of approximately 0.75 . Since the sum of orders in indan and in hydrogen is 1.5 (Fig. 2), the order in hydrogen is also 0.75 . This is a clear effect of increasing hydrogen pressure on the toluene kinetics and thus on the mechanism. With the hydrogen pressure the order in indan tends to rise from 0.5, while the order in hydrogen drops from 1 .

Further evidence was obtained from rate measurements by varing the hydrogen-indan molar ratio from 7.5 to 40 at a constant total pressure of 250 atm. The hydrogen pressure changed only slightly from 224 to $244 \mathrm{~atm}$, while the indan pressure ranged from 25.5 to $5.9 \mathrm{~atm}$. As Figure 5 shows, the rate data fit excellently to $r_{\mathbf{T}}$ and $r_{\mathrm{Pr}}$ :

$$
r_{\mathrm{T}}=k_{\mathrm{T}}[\text { indan }]^{0.75}[\text { hydrogen }]^{0.75}
$$

and

$$
r_{\mathrm{Pr}_{\mathbf{r}}}=k_{\mathrm{Pr}}[\text { indan] [hydrogen }]^{1.5}
$$

A further indication for the influence of the hydrogen pressure were the Arrhenius parameters. In Figure 6 a comparison was made between the data reported previously for a hydrogen pressure of $\approx 73 \mathrm{~atm}[1]$ and those obtained in this work for a hydrogen pressure of $\approx 230 \mathrm{~atm}$. Again the kinetics of propylbenzene turned out to be independent of the level of the hydrogen pressure, because both sets of data fitted to the same Arrhenius parameters of $A_{\mathbf{P r}}=4.3 \times 10^{5}$ and $E_{\mathbf{P r}} \ddagger$ 


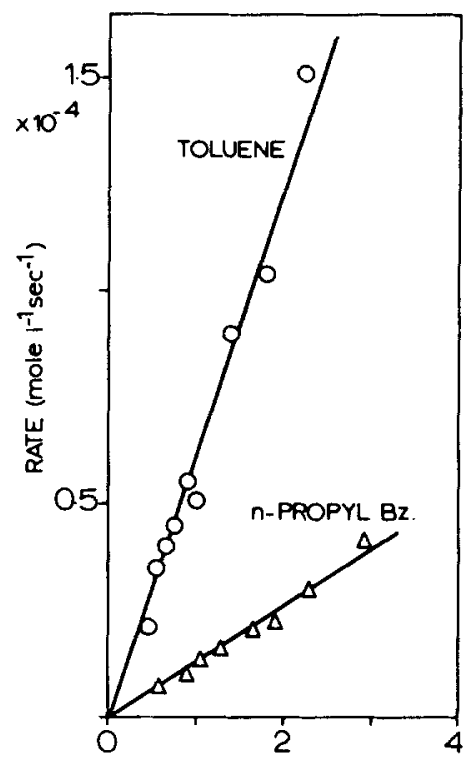

Figure 5. Formation rates of toluene and $n$-propylbenzene, as a function of indan and hydrogen concentration with varying molar ratios. Abscissa- $r_{\mathbf{T}}=$ $k_{\mathrm{T}}[\text { indan] }]^{0.75}$ [hydrogen] ${ }^{0.75} ; r_{\mathrm{Pr}}=k_{\mathrm{Pr}_{\mathrm{r}}}$ [indan] [hydrogen] ${ }^{1.5}$. Temperature $500^{\circ} \mathrm{C}$, total pressure constant at 250 atm, molar ratio hydrogen-indan 3.5 $=40$, indan pressures 41.0-5.9. atm $(=0.91-0.093 \mathrm{~mole} / 1$. $)$.

$=38 \mathrm{kcal} / \mathrm{mole}$. The toluene parameters, on the other hand, were affected markedly, because $A_{\mathrm{T}}$ increased by a factor of 10 to $3 \times 10^{10}$ with the hydrogen pressure and $E_{\Upsilon} \ddagger$ dropped slightly from $50 \mathrm{kcal} / \mathrm{mole}$ to $45-46 \mathrm{kcal} / \mathrm{mole}$.

\section{Discussion}

The $\alpha$ ring opening mechanism that was postulated previously [1] for the primary cracking reactions of indan is illustrated in Figure 1. It was selected, among others, mainly because of the good agreement between the theoretical kinetic equations (i.e., reaction orders) derived therefrom and the experimental data found so far. Also the effect of the hydrogen pressure on reaction orders and energies of activation, as described in this paper, can be very well explained with the same mechanism.

As an assessment of the experimental data, theoretical equations were derived for the $\alpha$ ring opening mechanism (Fig. 1) for different combinations of assumptions about the rates of the intermediate reactions (Table $\mathrm{I}$ ). 


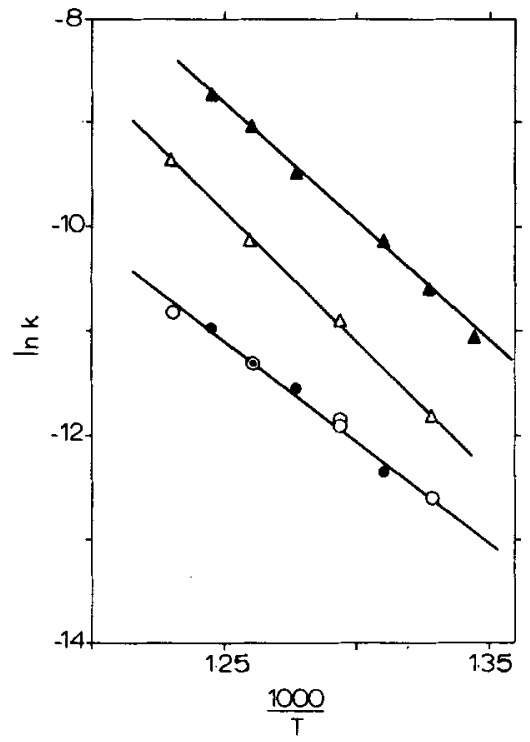

Figure 6. Arrhenius plots for formation of toluene $(\Delta, \boldsymbol{\Delta})$ and $n$-propylbenzene ( 0 , ๑). Empty symbols - total pressure 80 atm, hydrogen pressure $\sim 73$ atm; full symbols - total pressure $250 \mathrm{~atm}$, hydrogen pressure $\sim 230 \mathrm{~atm}$ (hydrogen pressure changes slightly with temperature).

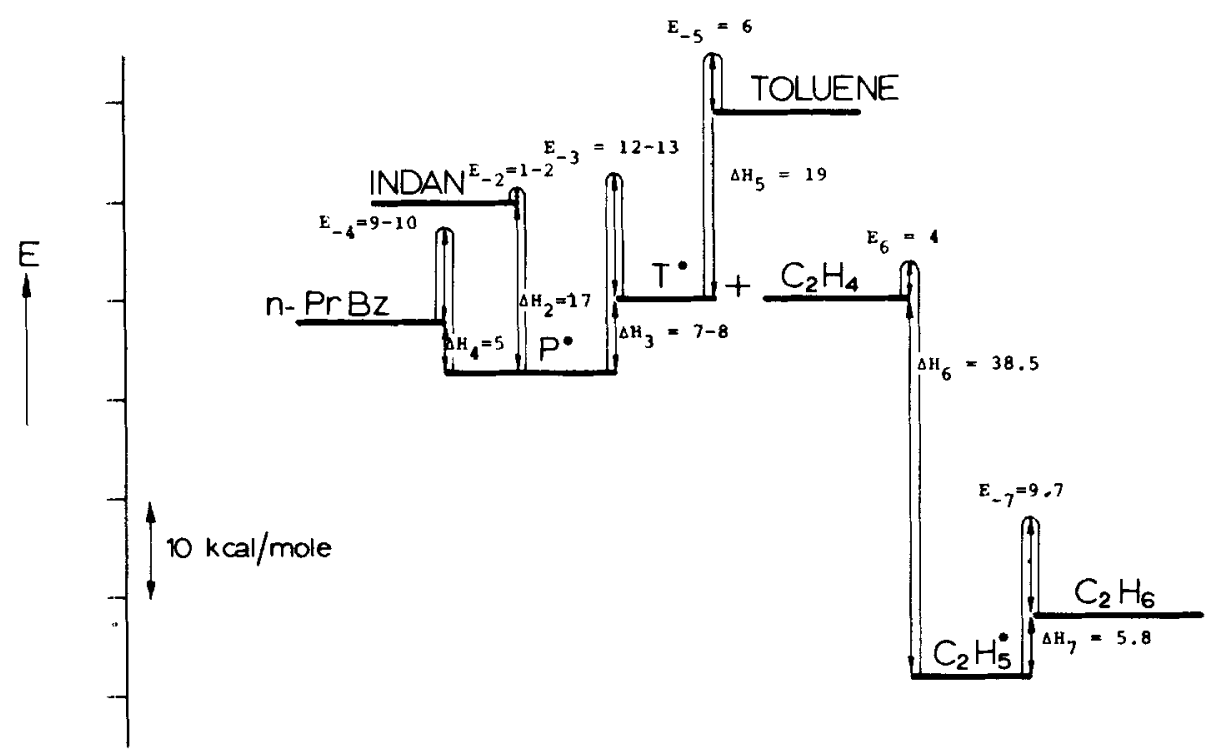

Figure 7. Energy diagram of $\alpha$ ring opening of indan. 
TABLE I

\begin{tabular}{|c|c|c|}
\hline & $\begin{array}{l}\text { Ratio of rates of proposed } \\
\text { Intermediate Reactions }\end{array}$ & $\begin{array}{c}\text { Rate equations of toluene and } \\
n \text {-Propylbenzene }\end{array}$ \\
\hline \multirow[t]{4}{*}{. } & $\begin{array}{l}\text { (a) } k_{-2} \gg k_{3}+k_{4}\left[\mathrm{H}_{2}\right] \\
k_{-3}\left[\mathrm{C}_{2} \mathrm{H}_{4}\right] \gg k_{5}\left[\mathrm{H}_{2}\right]\end{array}$ & $\begin{aligned} r_{\mathrm{T}} & =\left(2 K_{1} K_{2} K_{3} k_{5} k_{6}\right)^{0.5}[\mathrm{I}]^{0.5}\left[\mathrm{H}_{2}\right] \\
r_{\mathrm{P}_{\mathrm{T}}} & =\left(2 K_{1}\right)^{0.5} K_{2} k_{4}[\mathrm{I}]\left[\mathrm{H}_{2}\right]^{1.5}\end{aligned}$ \\
\hline & $\begin{array}{l}\text { (b) } k_{-2} \gg k_{3}+k_{4}\left[\mathrm{H}_{2}\right] \\
k_{-3}=0\end{array}$ & $\begin{aligned} r_{\mathrm{T}} & =\left(2 K_{1}\right)^{0.5} K_{2} k_{3}[\mathrm{I}]\left[\mathrm{H}_{2}\right]^{0.5} \\
r_{\mathrm{Pr}} & \left.=\left(2 K_{1}\right)^{0.5} K_{2} k_{4}[\mathrm{I}]\left[\mathrm{H}_{2}\right]\right]^{1.5}\end{aligned}$ \\
\hline & (c) $k_{-2}=0$ & $r_{\mathrm{T}}=\frac{\left(2 K_{1}\right)^{0.5} k_{2} k_{3}[\mathbf{I}]\left[\mathrm{H}_{2}\right]^{0.5}}{k_{3}+k_{4}\left[\mathrm{H}_{2}\right]}$ \\
\hline & $k_{-3}=0$ & $r_{\mathrm{Pr}}=\frac{\left(2 K_{1}\right)^{0.5} k_{2} k_{4}[\mathrm{I}]\left[\mathrm{H}_{2}\right]^{1.5}}{k_{3}+k_{4}\left[\mathrm{H}_{2}\right]}$ \\
\hline
\end{tabular}

A comparison with the experimental data, especially the reaction orders, shows that the effect of the hydrogen pressure, increasing up to $230 \mathrm{~atm}$, can be understood as a change in the rates of the intermediate reactions, that is a transformation of reaction (3) from reversible to irreversible ['Table $I(a),(b)$ ]. This transformation is explained by the reaction rate of the benzyl radical with molecular hydrogen [reaction (5)]. It is more enhanced by the hydrogen pressure than the formation rate of the benzyl radical. The latter increases with the square root of the hydrogen pressure only, while the former is linearly proportional to the hydrogen pressure.

Indeed as this theory forecasts [Table $\mathrm{I}(\mathrm{a}),(\mathrm{b})$ ], the rate equation for $n$-propylbenzene was found to be not affected by the hydrogen pressure. The slight but significant change in the reaction orders of toluene to values of 0.75 for both the indan and hydrogen order is also in good agreement with the theoretical forecast and indicates an intermediate regime in the transformation from a reversible to an irreversible reaction (3). Also the trends in the energies of activation observed with the hydrogen pressure follow immediately from the theoretical rate equations as listed in Table $I(a)$ and (b).

The energy diagram of the $\alpha$ ring opening is shown in Figure 7 (see also Appendix I). If reactions (2) and (3) are reversible $\left(P_{\mathrm{H}_{2}}<100 \mathrm{~atm}\right)$, the energies of activation can be written as [Table I(a)]

$$
E_{\mathrm{T}}=\frac{1}{2}\left(\Delta H_{1}+\Delta H_{2}+\Delta H_{3}+E_{5}+E_{6}\right)
$$

and

$$
E_{\mathrm{Pr}}=\frac{1}{2} \Delta H_{1}+\Delta H_{2}+E_{4}
$$

In the case of a reversible reaction (2) and an irreversible reaction (3) [Table I (b)] the energies of activation are

$$
E_{\mathrm{T}}=\frac{1}{2} \Delta H_{1}+\Delta H_{2}+E_{3}
$$


and

(XII)

$$
E_{\mathrm{Pr}}=\frac{1}{2} \Delta H_{1}+\Delta H_{2}+E_{4}
$$

So theoretically $E_{\mathrm{Pr}}$ does not change by the transformation of reaction (3), and this was also found in the experiments as Figure 6 illustrates. $E_{\mathrm{T}, b}$ however, differs from $E_{\mathrm{T}, a}$ by the term $\frac{1}{2}\left(\Delta H_{2}+E_{3}+E_{-3}-E_{5}-E_{6}\right)$, which equals -7 to $-9 \mathrm{kcal} / \mathrm{mole}$. So $E_{\mathrm{T}}$ is expected to decrease by approximately $8 \mathrm{kcal} / \mathrm{mole}$ when reaction (3) becomes irreversible. The data of Figure 6 indeed seem to support this because $E_{\mathrm{T}} \ddagger$ tends to decrease from 50 to $45-46 \mathrm{kcal} / \mathrm{mole}$ with increasing hydrogen pressure. The decrease of only $4-5 \mathrm{kcal} / \mathrm{mole}$ instead of the full 8 $\mathrm{kcal} /$ mole may also indicate an intermediate regime for reaction (3).

Although the mechanism proposed (Fig. 1) provides kinetic equations which meet a wide range of experimental data, it can be criticized on several points. One is the assumption of a steady state of ethylene, made in the derivation of rate equations for the "low hydrogen pressure region" [condition (a), Table I]. It furnishes a straightforward derivation of the rate equations of toluene and $n$ propylbenzene which are in agreement with experimental orders. However, apart from a few data points, no thorough experimental evidence is available to support the steady state of ethylene.

A second point of critism is the discrepancy between the actual experimental and the theoretical values of the overall activation energies for toluene and $n$ propylbenzene. Substitution of the elementary energy terms (Appendix I) in eqs. (IX) and (X) results in $E_{\mathrm{T}}=62 \mathrm{kcal} / \mathrm{mole}$ and $E_{\mathrm{Pr}}=50 \mathrm{kcal} / \mathrm{mole}$, whereas the experimental values are 50 and $38 \mathrm{kcal} / \mathrm{mole}$, respectively. The difference of $E_{\mathrm{T}}$ and $E_{\mathrm{Pr}}$, however, is identical in both the experimental and the theoretical case, and this indicates that the discrepancy in the absolute values can be allocated to the common term $\frac{1}{2} \Delta H_{1}$. So instead of $52 \mathrm{kcal} / \mathrm{mole}$ a value of $40 \mathrm{kcal} / \mathrm{mole}$ seems to be more apparent for the energy term in eqs. (IX)-(XII), which is contributed by the initiation and termination reactions. Numerous initiation reactions, other than $\mathrm{H}_{2} \rightarrow 2 \mathrm{H}$, were considered such as indan $\rightarrow$ indanyl radical $+\mathrm{H}, \mathrm{H}$ transfer between two indan molecules resulting in $\mathrm{P}^{\bullet}$ and indanyl radical, and bimolecular reaction of $\mathrm{H}_{2}$ with indan into $\mathrm{P}^{\bullet}$ and $\mathrm{H}$. They were all combined in a systematic way with termination reactions such as $\mathrm{H}+\mathrm{H} \rightarrow \mathrm{H}_{2}, \mathrm{P}^{\bullet}+\mathrm{P}^{\bullet} \rightarrow \mathrm{PP}, \mathrm{T}^{\bullet}+\mathrm{T}^{\bullet} \rightarrow \mathrm{TT}, \mathrm{P}^{\bullet}+\mathrm{T}^{\bullet} \rightarrow \mathrm{PT}$, etc. Also alternative propagation steps such as $\mathrm{P}^{\bullet}+$ indan $\rightarrow$ indanyl radical $+\mathrm{P}$ and $\mathrm{T}^{\bullet}$ + indan $\rightarrow$ indanyl radical $+\mathrm{T}$ were considered. The rate equations resulting from a steady-state approach to all possible combinations were very complicated. Although certain equations approached better the experimental activation energies, they all failed with respect to the reaction orders and the interpretation of the hydrogen pressure effects. Only a set of initiation and termination reactions which can be expressed overall by $\mathrm{H}_{2} \leftrightharpoons 2 \mathrm{H}$ gave the best agreement with the reported kinetic findings, except for the energies of activation. Therefore, 
and because of the extremely low reaction rate at the prevailing conditions, a direct thermal dissociation of $\mathrm{H}_{2}$ into $\mathrm{H}$ atoms is most unlikely as initiation reaction. An indirect dissociation seems more realistic under the reported conditions, for example, the reaction system that was suggested previously [1], that is, indan $\rightarrow$ indanyl radical $+\mathrm{H}$ and indanyl radical $+\mathrm{H}_{2} \rightarrow$ indan $+\mathrm{H}$. Unfortunately this indirect route also meets the experimental reaction orders only when both reactions are assumed to be in established equilibrium. Thus af ter evaluating all initiation/termination reactions proposed, one must conclude that the system $\mathrm{H}_{2} \rightarrow 2 \mathrm{H}$ and $\mathrm{H}+\mathrm{H} \rightarrow \mathrm{H}_{2}$ is not in thermodynamical equilibrium (a sample calculation in Appendix II seems to confirm this) and that the dissociation of $\mathrm{H}_{2}$ does not occur by direct thermal fission or indirectly via a radical intermediate.

Maybe a definite solution to the problem can be found in an effect which has not yet been considered in the preceding discussion, namely, the participation of the reactor wall. Extensive experimental work which was reported elsewhere [13] found that the hydrocracking does not proceed without an "active" reactor wall and that initiation and termination reactions must be wall-catalyzed reactions. Thus the interpretation of the afore-mentioned data in terms of a purely homogeneous gas reaction is incorrect. Further, preliminary experiments with deuterium show that the $\mathrm{H}_{2} / \mathrm{D}_{2}$ interchange, also in the absence of indan, is very fast, much faster than the rate of hydrocracking and $H / D$ exchange between $D_{2}$ and indan.

Although it is felt that the governing initiation and termination reactions are most probably a wall-catalyzed dissociation of $\mathrm{H}_{2}$ and wall recombination of $\mathrm{H}$ atoms, a definite solution to the problem of the "low" energies of activation cannot be given at the present stage of the investigation.

\section{Appendix I}

In the following list $\Delta H_{n}$ stands for the heat of reaction in direction $n$, and $E_{n}$ and $E_{-n}$ are the energies of activation in directions $n$ and $-n$, so that $E_{n}-E_{-n}=$

$\Delta \mathrm{H}_{n}{ }^{2}$

$\Delta H_{1}=104 \mathrm{kcal} / \mathrm{mole} \mathrm{[5]}$

$\Delta H_{2}=-17 \mathrm{kcal} / \mathrm{mole}$

$E_{2}=1-2 \mathrm{kcal} /$ mole, estimated in analogy with $\mathrm{H}$-atom addition to toluene and xylenes [6]

$\Delta H_{3}=7-8 \mathrm{kcal} / \mathrm{mole}$

$E_{3}=20 \mathrm{kcal} / \mathrm{mole}[7]$

$\Delta H_{4}=5 \mathrm{kcal} / \mathrm{mole}$

${ }^{2}$ The values of $\Delta \mathrm{H}_{2}, \Delta \mathrm{H}_{3}, \Delta \mathrm{H}_{4}$, and $\Delta \mathrm{H}_{5}$ resulted from thermodynamic calculations as described in the literature $[7,8]$. 
$E_{4}=14-15 \mathrm{kcal} / \mathrm{mole}$, from $\Delta H_{4}$ and $E_{-4}=9 \mathrm{kcal} / \mathrm{mole}$, estimated in analogy with $\mathrm{H}+\mathrm{C}_{3} \mathrm{H}_{8} \rightarrow \mathrm{H}_{2}+\mathrm{C}_{3} \mathrm{H}_{7}$ and $\mathrm{H}+\mathrm{C}_{4} \mathrm{H}_{10} \rightarrow \mathrm{H}_{2}+\mathrm{C}_{4} \mathrm{H}_{9}[5,9]$

$\Delta H_{5}=19 \mathrm{kcal} / \mathrm{mole}$

$E_{5}=25 \mathrm{kcal} / \mathrm{mole}$, from $\Delta H_{5}$ and $E_{-5}=6 \mathrm{kcal} / \mathrm{mole}[10]$

$\Delta H_{6}=-38.5 \mathrm{kcal} / \mathrm{mole}[5]$

$E_{6}=4.1 \mathrm{kcal} / \mathrm{mole}$

$\Delta H_{7}=5.8 \mathrm{kcal} / \mathrm{mole}[5]$

$E_{7}=15.5 \mathrm{kcal} / \mathrm{mole}$, from $\Delta H_{7}$ and $E_{-7}=9.7 \mathrm{kcal} / \mathrm{mole}[7]$

\section{Appendix II}

The steady-state concentration of $\mathrm{H}$ atoms was calculated for the following set of conditions: temperature $540^{\circ} \mathrm{C}, \mathrm{P}-$ indan $=7.0 \mathrm{~atm}(=0.1058 \mathrm{~mole} / 1 \mathrm{l})$, $\mathrm{P}-\mathrm{H}_{2}=73 \mathrm{~atm}(=1.058 \mathrm{~mole} / \mathrm{l}$. $)$.

In the steady state the formation rate of toluene $r_{\mathrm{T}}$ is the rate of hydrogenation of $\mathrm{C}_{2} \mathrm{H}_{4}=k_{6}[\mathrm{H}]\left[\mathrm{C}_{2} \mathrm{H}_{4}\right] r_{\mathrm{T}}$ was found to be $3.2 \times 10^{-5} \mathrm{~mole} / 1$. $\cdot \mathrm{sec} ;\left[\mathrm{C}_{2} \mathrm{H}_{4}\right]$ was on the average $2 \times 10^{-3}$ mole/l. over an indan conversion range of $15 \%$. From literature data $k_{6}$ resulted as $2.5 \times 10^{9} \mathrm{l} / \mathrm{mole} \cdot \mathrm{sec}[11]$ or $1.29 \times 10^{10} \mathrm{l} / \mathrm{mole} \cdot \mathrm{sec}$ [5] at $540^{\circ} \mathrm{C}$. Thus the steady-state concentration $[\mathrm{H}]$ is $6.4 \times 10^{-12} \mathrm{~mole} / 1$. or $1.24 \times 10^{-12}$ mole/l., depending on the value of $k_{8}$.

Thermodynamic equilibrium values of $[\mathrm{H}]$ were calculated according to two different references, namely,

$$
K_{c}=3970 \exp (-104.400 / R T)
$$

and

$\left.\log K_{c}=(\Delta S-\Delta n R(1+2.3 \log R T) / 2.3 R)-[\Delta H-\Delta n R T) / 2.3 R T\right]$

where $K_{c}$ is the equilibrium constant defined as $[\mathrm{H}]^{2} /\left[\mathrm{H}_{2}\right]$ in moles per liter. The average for $[\mathrm{H}]$ from both calculations was $5-6 \times 10^{-13} \mathrm{~mole} / 1$. Thus the steady state $[\mathrm{H}]$ seems to be slightly higher than $[\mathrm{H}]$ equilibrium, although its significance is questionable regarding the variation in the literature data for $k_{6}$.

\section{Acknowledgment}

The authors are indebted to J. M. Alberigs and A. H. Pleiter for the construction of the high-pressure reaction system.

\section{Bibliography}

[1] J. M. L. Penninger and H. W. Slotboom, Rec. Trav. Chim. Pays Bas, 92, 513 (1973).

[2] E. Oltay, J. M. L. Penninger, and P. G. J. Koopman, Chimia, 27, 318 (1973). 
[3] E. Oltay, J. M. L. Penninger, and W. A. N. Konter, J. Appl. Chem. Biotech., 23, 573 (1973).

[4] J. M. L. Penninger and H. W. Slotboom, Erdöl u. Kohle, 24, 445 (1973).

[5] J. A. Kerr and M. J. Parsonage, "Evaluated Kinetic Data on Gas Phase Addition Reactions", Butterworth, London, 1972.

[6] S. W. Benson and R. Shaw, J. Chem. Phys, 47, 4052 (1967).

[7] S. W. Benson, "Thermochemical Kinetics," Wiley, New York, 1968, p.151.

[8] H. E. O'Neal and S. W. Benson, in "Free Radicals," vol. II, J. K. Kochi Ed., Wiley, New York, 1973, ch. 17, pp. 275-360.

[9] Z. G. Szabó, "Fortschritte in der Kinetik der homogenen Gasreaktionen," Steinkopf, Darmstadt 1961, p. 49 .

[10] S. W. Benson and G. R. Hougen, J. Phys. Chem. 71, 4404 (1967).

[11] K. Yang, J. Amer. Chem. Soc. 84, 719 (1962).

[12] C. C. Zimmerman and R. York, Ind. Eng. Chem. Proc. Des. Dev. 3, 254 (1964).

[13] H. W. Slotboom and J. M. L. Penninger, Ind. Eng. Chem, Proc. Des. Dev, 13, 296 (1974).

Received December 14, 1973.

Revised October 1, 1974. 